\title{
Mathematical Analysis Method for Stock Market Using MA and KDJ Indicator
}

\author{
Man Yuan ${ }^{1}$ \\ ${ }^{1}$ Department of Mathematics, Hong Kong Baptist University, Hong Kong \\ Correspondence: Man Yuan, Department of Mathematics, Hong Kong Baptist University, Hong Kong.
}

Received: July 20, 2019

Accepted: July 29, 2019

Online Published: August 2, 2019

doi:10.20849/abr.v4i2.618

URL: https://doi.org/10.20849/abr.v4i2.618

\begin{abstract}
With the rapid development of Economic Globalization as well as international trade and capital transaction, stock market take a more and more important position in the finance analysis.

In this thesis, I combined the MA the KDJ, MA for long term trend analysis and KDJ for short term analysis. First I introduced MA and KDJ separately, their strength and weakness. Then I try to put them together, adjust the parameters to make them suitable for Shanghai Stock Exchange Composite Index.

Then I use my model to simulate transaction in real world, estimate the rate of return and comparing with the stocks' holding rate and inflation rate. The result is pleasant. At last, I give a conclusion and a further advice to this model.
\end{abstract}

Keywords: MA, KDJ, technical analysis, stock market

\section{Introduction}

With the rapid development of Economic Globalization as well as international trade and capital transaction, stock market take a more and more important position in the finance analysis. Firstly, stock market is a main part of national investment, absorbing a large quantity of private capital. Secondly, it is the standard for almost all the finance derivatives, influence billions of transaction. At last, it shows the operating condition of the national economy to a certain extent.

Technical analysis is one of the most heated methods in stock market research, which has proved itself many times. In technical analysis, we talk about trends and signal. Everyone knows, if you have known an asset's price will increase in advance, you will buy it to gain profit in future; and vice versa for decrease. However, financial markets are full of uncertainty, so we use technical analysis to forecast the trend. For some sophisticated model, they simplify the forecast result into some signal, to tell you should buy or sell, which means more people without finance background can take part in the capital market.

There are many available indicators for technical analysis, such as RSI, Bollinger Bands, MACD, KDJ etc., but each of them has strength and weakness. MACD is the most classical model, it need a long-period data and can give a judgement to the general trend. It does well in long term, makes mistake rarely, but will be obtuse in short term. And oppositely, KDJ is quite sensitive to the price volatility. It performed well in short term, but in long term high sensitivity means too frequent transactions and too much transaction fee.

In practice, people seldom use one kind of indicators, the more usual way is applying several indicators together. So I tried to combine MACD and KDJ, using MACD for defining the trend and KDJ for deciding the accurate transaction plot. And to make the conclusion more universal, I use the Shanghai stock market in examples below rather than a certain stock.

\section{Technical Indicators: MA and KDJ}

\subsection{Moving Average (MA) Process}

Moving Average model is classical in technical analysis, also the foundation for many complicated model. Generally, we take several former data and calculate the average value. For example, if we want to get MA (5), take five items forwards and calculate the average of them. The formula for MA is: 


$$
M A(p)_{t}=\frac{1}{p} \sum_{i=0}^{P-1} M A_{p-i}
$$

Thus, if we draw two graphs, one for MA line and one for real data, we can see that the MA line will be smoother because the process of taking average will reduce the impact of extreme values. In Figure 1, we draw the MA (10) graph for SSE index and the shape of them is Intuitive:

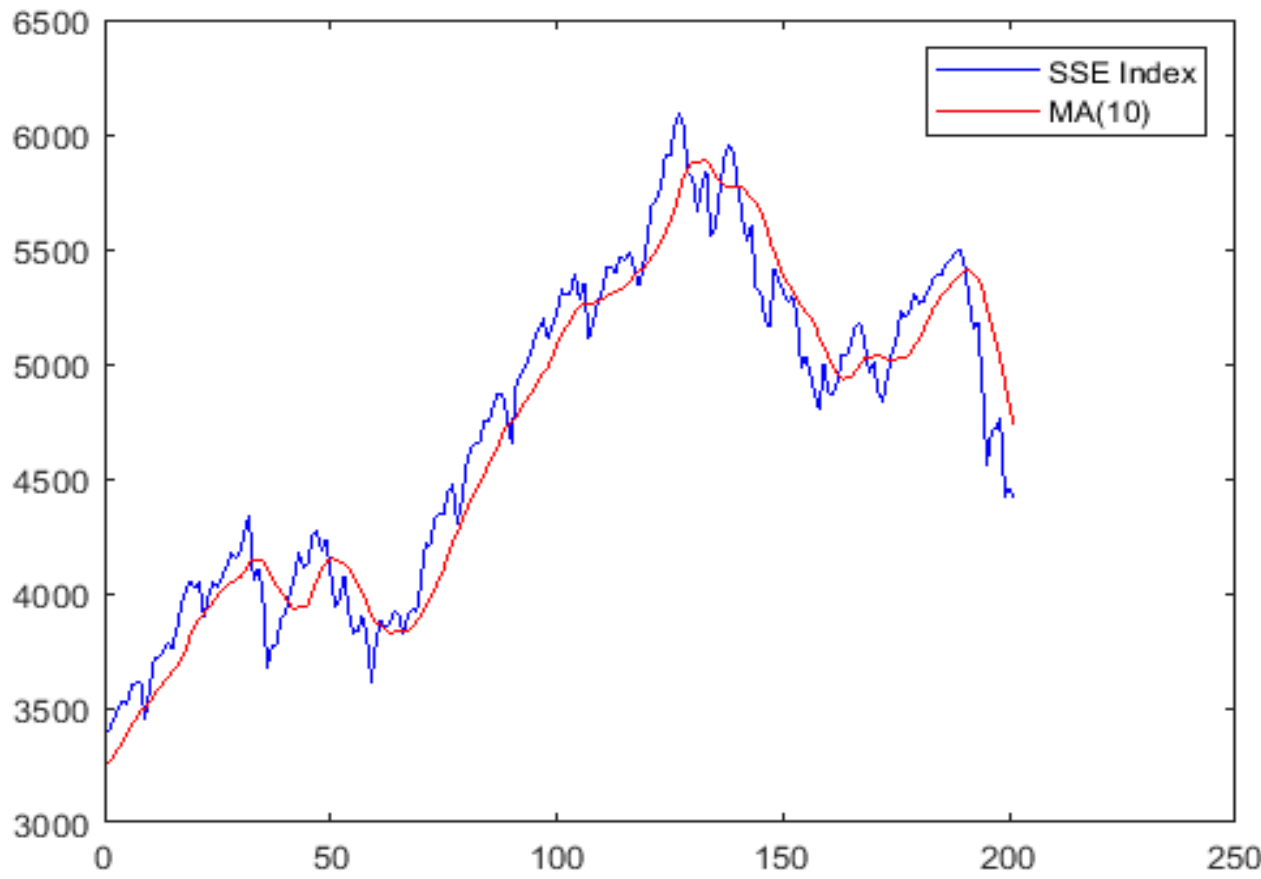

Figure 1

Then, for data in a certain period, we can draw several MA lines using different MA lag p. Figure 2 is the graph for different MA lag. It is clear that MA (20) is the flattest one, then the MA (10), then MA (5). That means MA (5) is the most sensitive for the latest variation, the MA (20) is the most obtuse. 


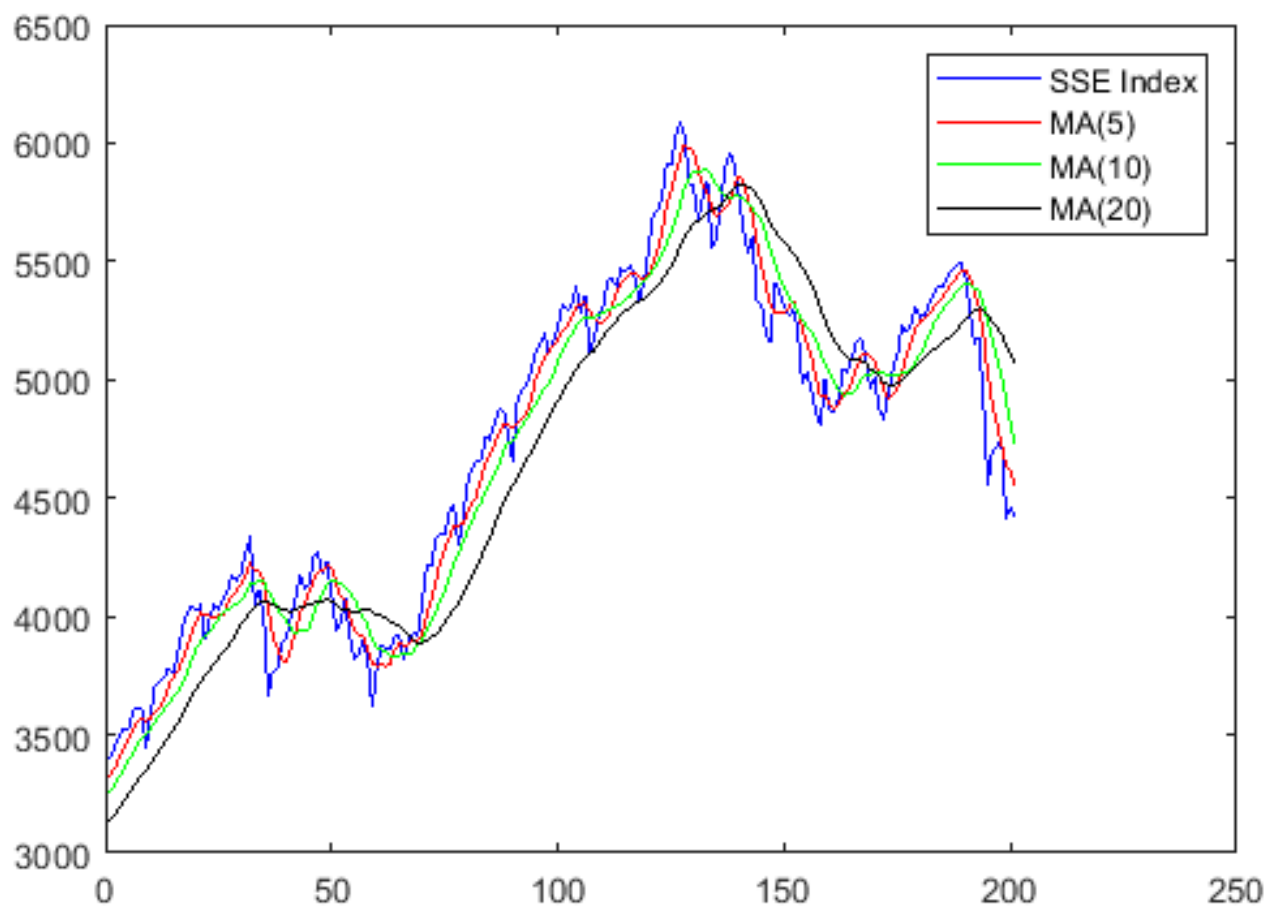

Figure 2

\subsubsection{Golden Cross and Death Cross}

Suppose now we are in stable period, but suddenly, we come into a fierce increasing interval, which means the latest price will pull the average value up, and obviously, the rise of MA (5) must be greater than MA (20). Thus, if the lines is parallel before, in rising interval the short term MA will cross the long term one from bottom to top (we call this golden cross); vice versa, if we are in a fall interval, the short term MA will cross the long term one from top to bottom (we call it death cross), which is shown in Figure 3. 


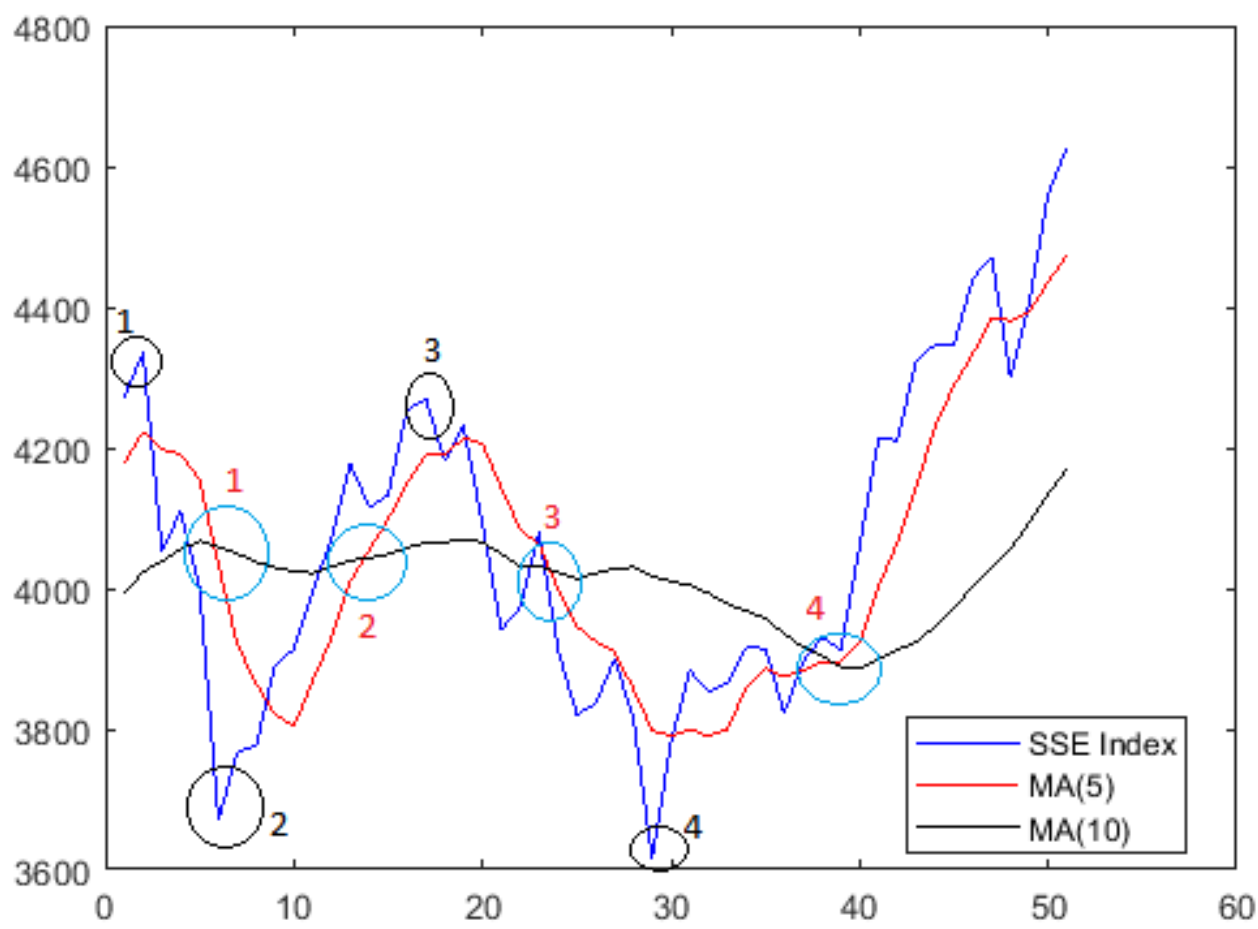

Figure 3

The blue circle with red text means the cross of MA line, 2 and 4 are golden cross which means uptrend, while 1 and 3 are death cross which means downtrend. However, take the first cross as example, the downtrend begin with the first black circle, but we got the downtrend signal in blue circle 1. So that means the MA model has hysteresis, we get the signal after the trend has started for a while.

That is the main weakness of MA model, it can always tell you a right result, but after a while. Look at the death cross 1 and the black bottom 2, they are quite closed, which means the market rebound just after we get the falling signal, you will be misled. Even worse, if you follow the cross 2 and 3, you will lose money actually. 


\subsubsection{MA in Trend Identification}

The cross in MACD is the signal of the variation of trend. So what will happen if we are in a steady increasing or decreasing trend? I choose a section of surging interval and draw a MA graph as Figure 4:

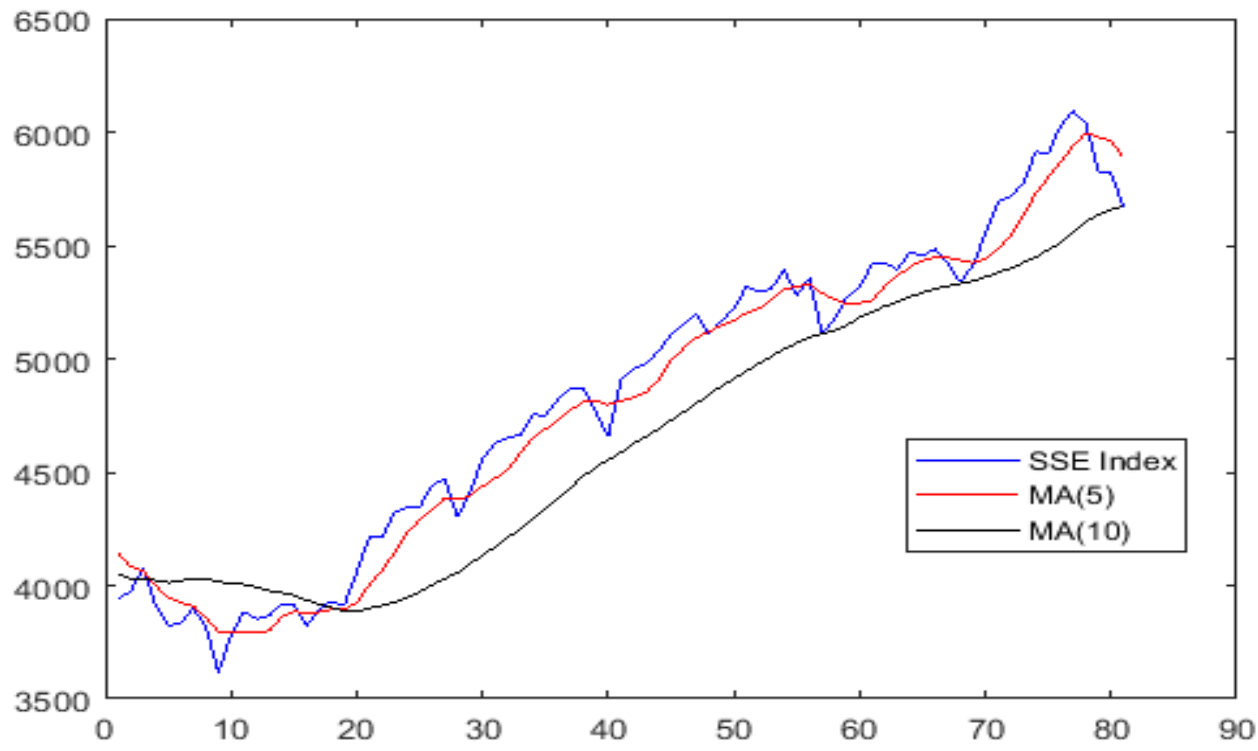

Figure 4

In this graph, after the golden cross in $\mathrm{t}=20$, the MA (5) line is always above the MA (20) line, and the index keeps rising. So if after the golden cross, we see the short term line stay above the long term line, that means the trend for rising will keep for a while, until a death cross appear.

So that is quite interesting that if the price has a low volatility (i.e. no too much concussion, but keeps rise or fall generally), the MA model will be efficient. But in practice, no one knows we will be in concussion or stability.

And vice versa, after a death cross, if the short term line keeps below the long term line, that means a long period recession: 


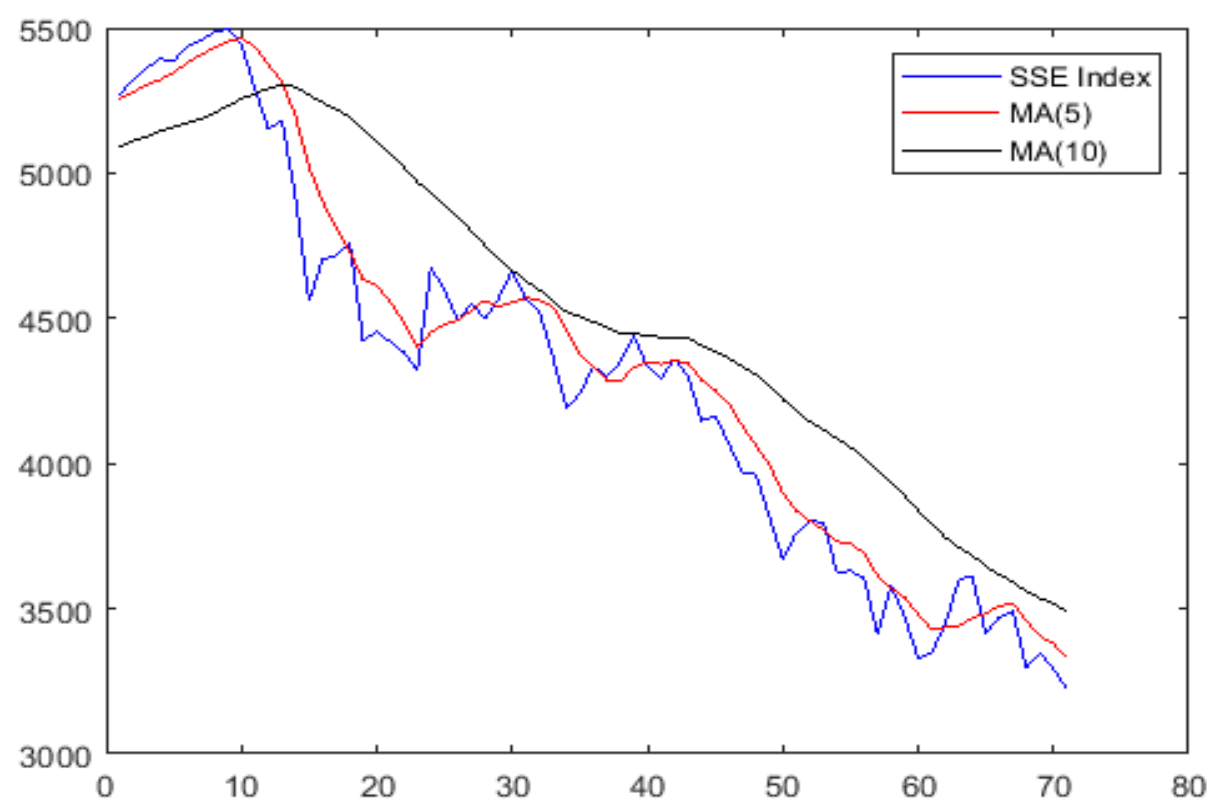

Figure 5

For MA, the cross is signal for buying or selling, and the trend is signal for not buying or selling. In Figure 5, we can see there're several suspected rebounding, but if we focus on the MA line, the short line is still lying below, so that means the price will keep falling for a while, any buying operation needs to be cautious.

\subsubsection{Feature of MACD}

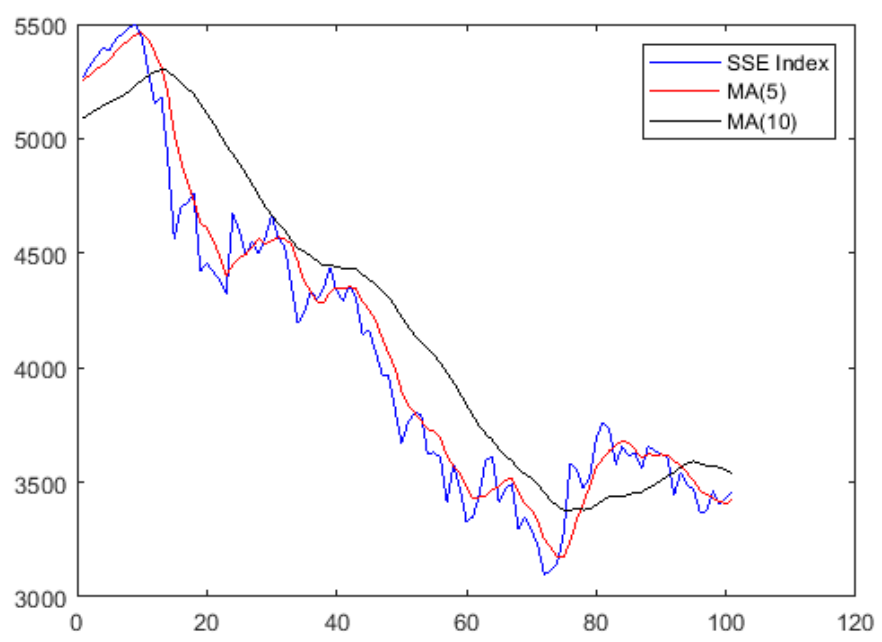

Figure 6

So we extend the former example for a while, see what will happen next. In $\mathrm{t}=79$, a golden cross appear, which means this long recession come to an end. However, the short term line goes down rapidly and led a new death 
cross. Similar to the example in 2.1.1, suppose that we strictly follow these signal, so we will operate twice as below:

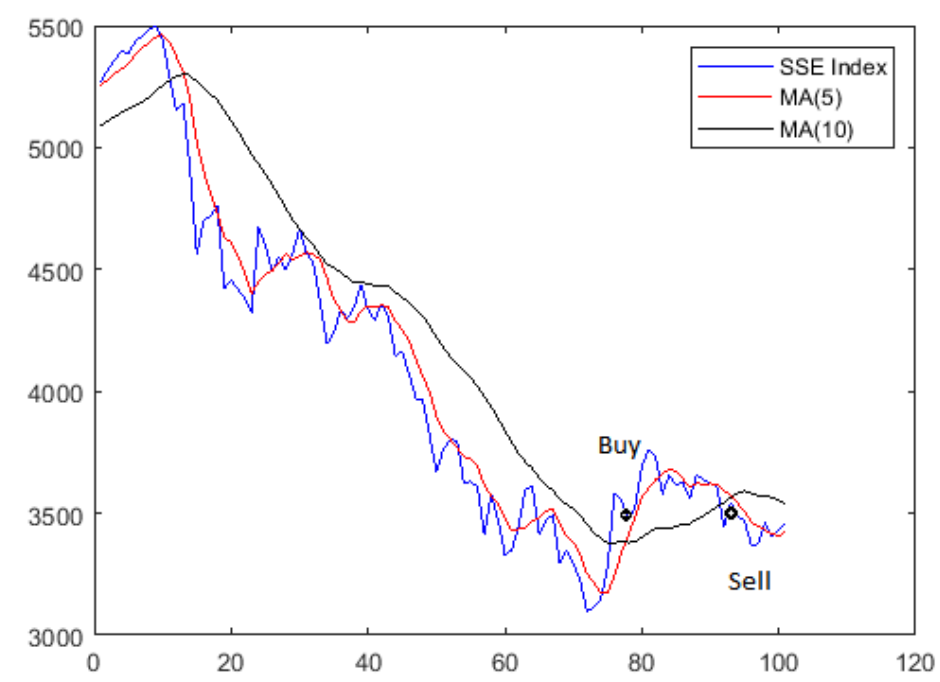

Figure 6

The buying and selling points have been marked out, the price of them are closed, in fact you will lose money because of the transaction fee. Combined with the Cross part, we get the conclusion that the cross signal is not always reliable, you need more information and judgement.

However, the trend signal is more reliable because it is a prevent signal, so the request for accuracy is wider. In these examples, trend signals will help you escape from a severe recession and prevent you leaving the market too early to lose potential gains.

Therefore, in my mixed model, I use MA model to identify the trend and KDJ model for the accurate operations. The KDJ model is quite sensitive to the variation, we will talk about it next part.

\subsection{KDJ Model}

$\mathrm{KDJ}$ is a technical indicator using stochastic method to forecast the price and trend of a certain asset. MA model is totally made from former data, but KDJ use some random variables so that you can get a more accurate result.

First we define Row Stochastic Value (RSV), which means the probability for current price. The formula of RSV is:

$$
R S V_{t}=\frac{\left(C_{t}-L_{t(n)}\right)}{\left(H_{t(n)}-L_{T(t)}\right)} \times 100
$$

\section{$C_{t}$ means the current price}

\section{$L_{t(n)}$ means the lowest price in former $t$ days}

\section{$H_{t(n)}$ means the highest price in former $t$ days}

The standard value for RSV is 50, which means the future price will stay stable. If we get a value greater than 50 , that means the probability of rising is higher than falling; and vice versa for RSV less than 50.

Using RSV, we make up three line K, D and J as below: 


$$
\begin{gathered}
K_{t}=\frac{2}{3} \times K_{t-1}+\frac{1}{3} \times R S V_{t} \quad D_{t}=\frac{2}{3} \times D_{t-1}+\frac{1}{3} \times K_{t} \\
J_{t}=3 \times K_{t}-2 \times D_{t}
\end{gathered}
$$

$\mathrm{K}$ is the function about RSV and itself, D is calculated from K and $\mathrm{J}$ is calculated from K and J. In practice, $\mathrm{J}$ is the fastest line, then the line $\mathrm{K}$, and $\mathrm{D}$ line is the slowest line. Correspondingly, $\mathrm{J}$ is most sensitive to the variation of price and $\mathrm{D}$ is the dullest one.

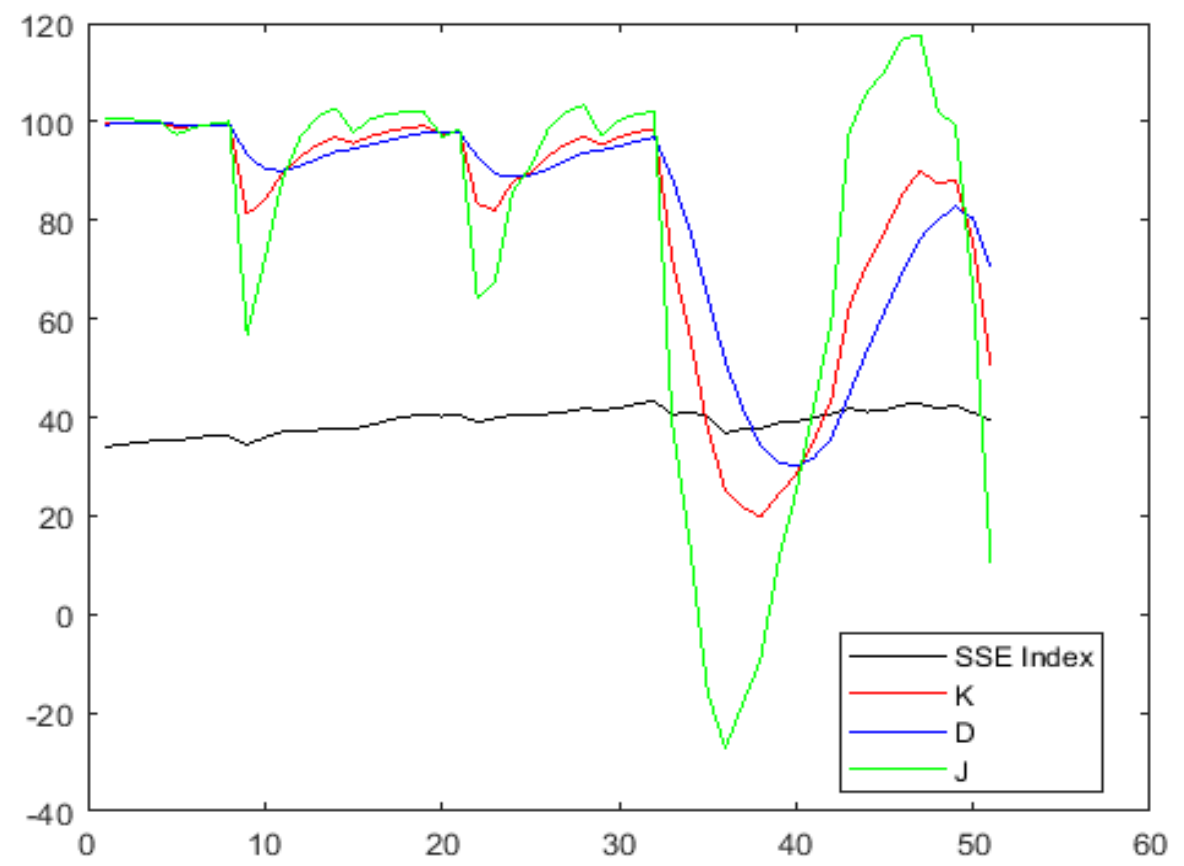

From the graph, the SSE seems flat but all the three lines have a drastic fluctuation, which means the KDJ model is quite sensitive. The green line $\mathrm{J}$ is especially active and the blue line $\mathrm{D}$ has a least volatility.

Some signals of KDJ about overbought and oversell have been shown below:

I. When $K \geq 80, D \geq 80, J \geq 100$, which means there's no increasing space, the signal of selling appears. And vice versa, when $K \leq 20, D \leq 20, J \leq 0$, there's no decreasing space, the signal of buying appears.

II. Death Cross for KDJ

If $\mathrm{K}$ and $\mathrm{J}$ fall across the line $\mathrm{D}$ (which means death cross), we get the buying signal, the internal logic is the latest price had an obvious decreasing trend, $D_{t} \geq 80$ means no sufficient rising space, the asset has a great possibility to fall. 


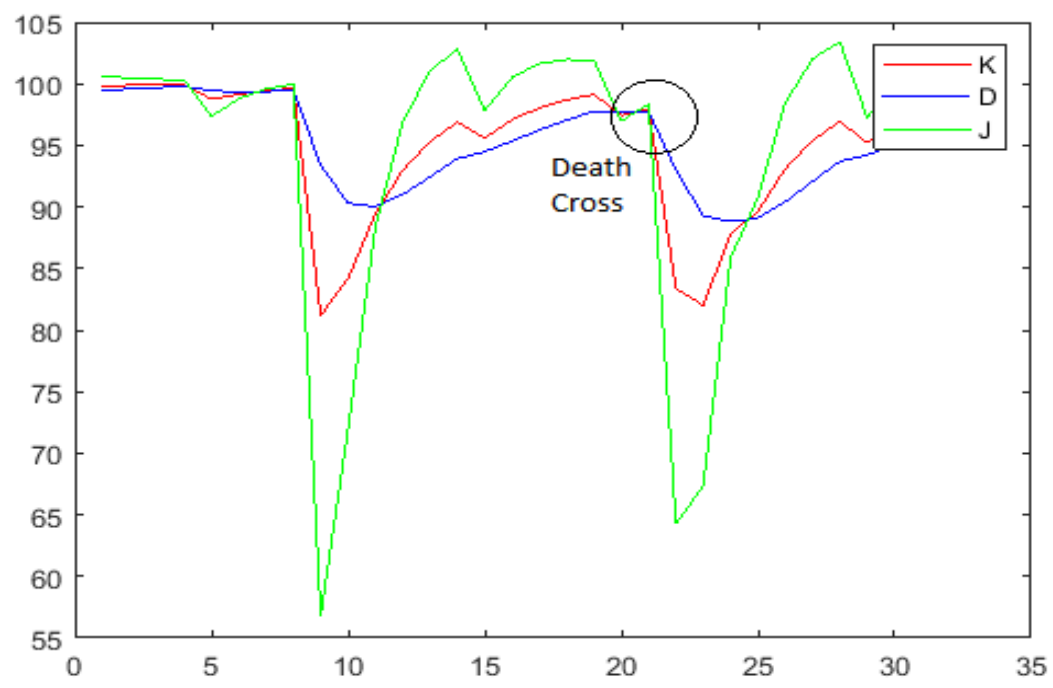

Figure 7

In fact, the KDJ is too sensitive: in Figure 7, we can see 4 crosses in 30 days data. The transaction fee will be high and it is hard for investor to earn money.

III. III Golden Cross for KDJ

If $\mathrm{K}$ and $\mathrm{J}$ rise across the line $\mathrm{D}$ (which means golden cross), vice versa, we get the buying signal, the internal logic is the latest price had an obvious increasing trend, $D_{t} \leq 20$ means sufficient rising space.

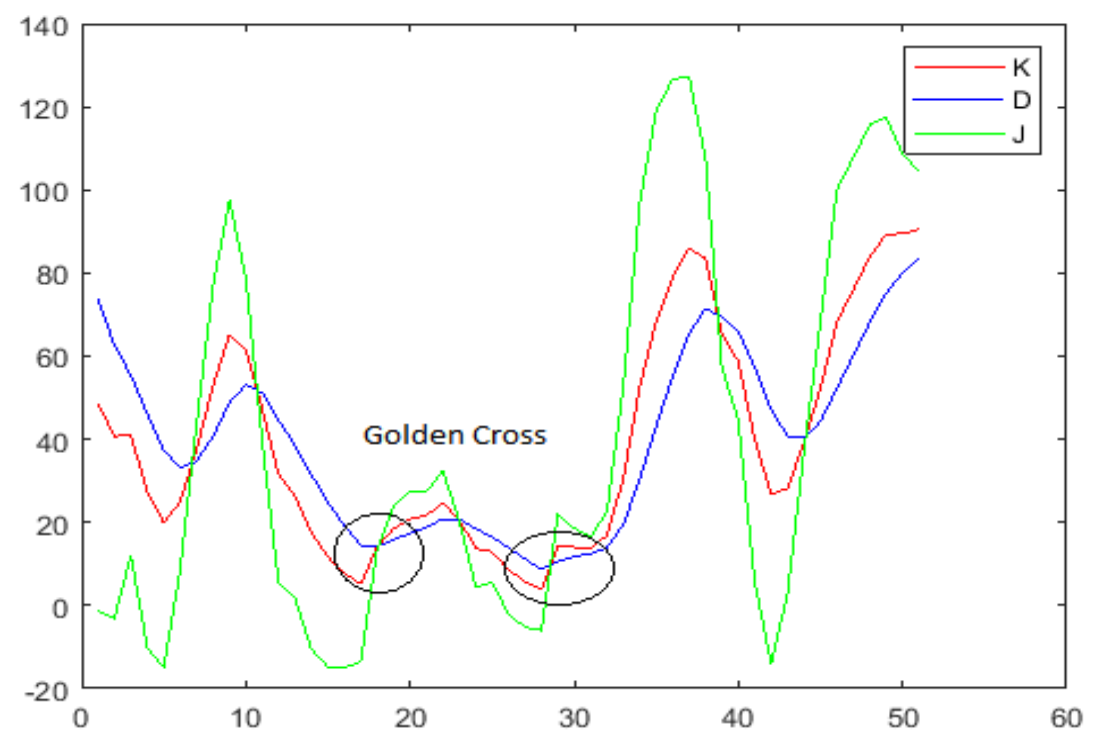

Figure 8 
In Figure 8, we get two golden cross in nearly 10 days. But in fact, if you long the stock at the first golden cross, it rise in a very short time (about 2 days), and then fall across the line D. However, after second golden cross, the price increase fiercely. It is clearer in Figure 9, the first transaction is more profitable than the second one.

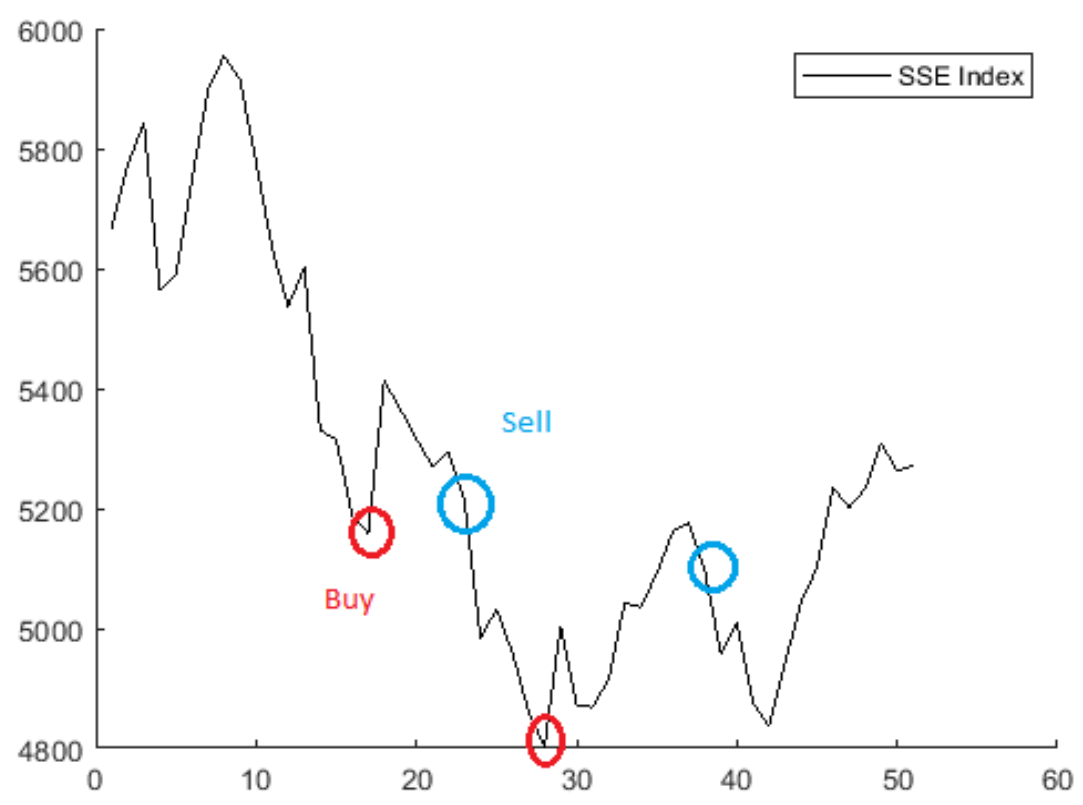

Figure 9

Therefore, the problem for KDJ is just opposite to the MA, sometimes it is too sensitive to operate, that means you will buy or sell frequently at when is mostly not a good enough transaction point. In other word, they seems similar but some can help earn great amount money but some cannot and even you will lose your transaction fee.

Thus, I get the idea to make a MA-KDJ mixed model, a hysteretic model and a sensitive model can be an excellent pair that complements each other: KDJ model can point out the overbuying or overselling opportunities that MA missed, and MA trend analyse can prevent KDJ from over-frequent transaction.

\section{The Technical Model}

\subsection{Assumptions}

Before introducing the model and simulating in real world, we first list some assumptions to make the model and simulation clearer.

1. I take the Shanghai Stock Exchange Composite Index as the simulation asset, to show that the model is not specific to any certain category of stocks.

2. The initial capital equals to the initial SSE index, so it is easy to check if we can get an excess profit compared with the holding return.

3. The transaction fee is $0.25 \%$ of the transacted stock current value no matter buying or selling.

4. We take on trading day as the time unit, which means one trading day is non-splittable, thus we can only do transaction one time a day, no matter buying or selling. And similarly, we use the close price as the price for a certain trading day.

5. To simplify the process, we follow all-in-all-out rule.

6. The floating profit and loss is not reliable, so we don't calculate the profit until we sell out the stocks, and before selling the asset value keeps the value you brought in.

7. We ignore the dividends and if we hold any shares of stock at the end of simulation, sell it all. 


\subsection{The Application for MA and KDJ}

Generally, we use the MA model to identify the trend, which can be divided into bull market, bear market and stable market. And in different trend we give different tolerance space to the KDJ model. In a determined bull or bear market, KDJ has a greater authority to make a transaction. The reason is:

i. In bull market, you may do a valid trade (i.e. escape from the peak) or an invalid trade pair (i.e. you sell out the stock, then it keeps rising, so you have to buy it back). If invalid, you lose some profit but you still earn money; but if valid, you can avoid maybe a huge amount of money.

ii. In bear market, usually we keep a wait-and-see attitude, and at the end of bear market there is always a bottom rebounding. So you may miss the chance to buy at bottom.

But in stable period, we must be careful, because the price will vary rapidly, so it's hard to catch the trend. The error of the model will be magnified, we may do some wrong transactions. And at the same time, the volatility is low so that the profit space is narrow, so the transaction fee will take a bigger proportion.

\subsubsection{How to Identify the Trend}

In my model, I use three MA lines: short, middle and long term, to make the forecast more accurate. As we said in the first part, when the short and middle lines rise across the long term line and keep for a while, it means a bull market. Vice versa, short and middle lines fall across the long term one means a bear market (Figure 10). If there's no these significant symbols, I regard it as a stable stage.

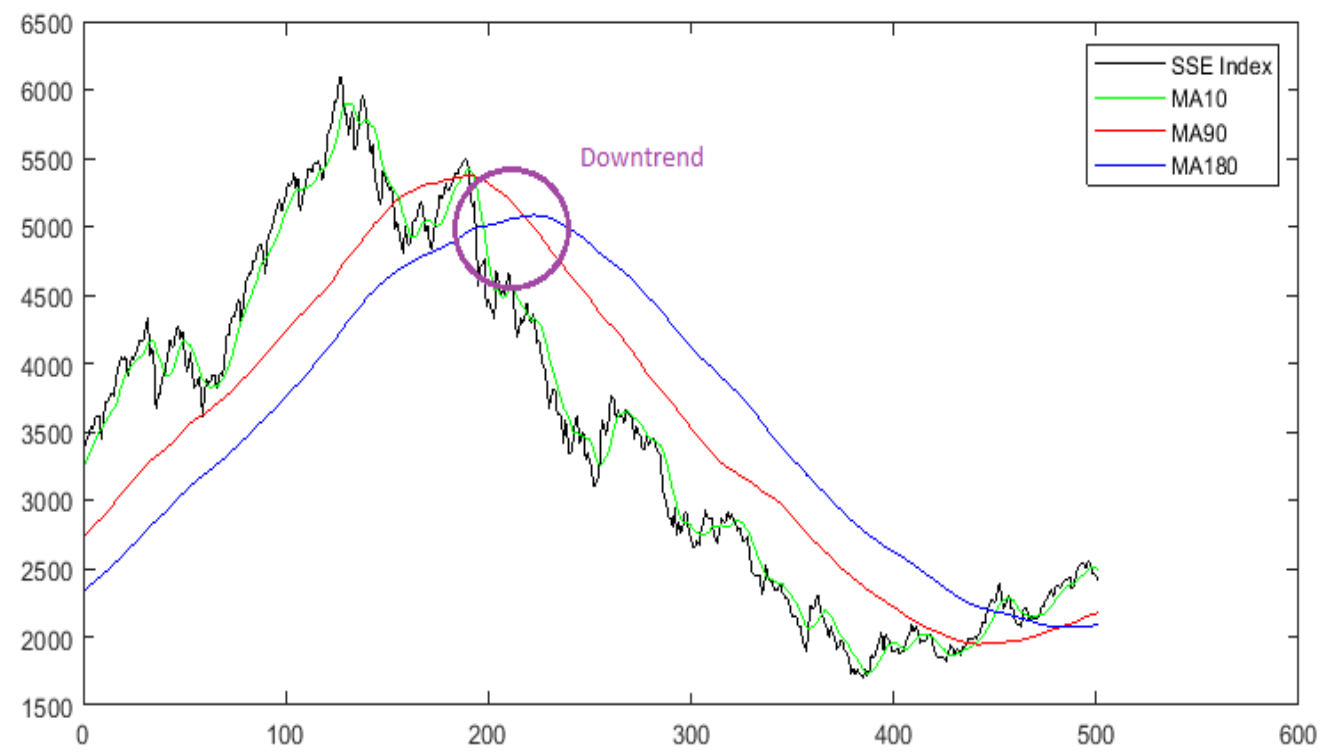

Figure 10

The choice of three values must expand or shrink simultaneously. If the short line is very small and the long line is very large, then the changes in the three lines will not be synchronized, affecting the overall performance of the model.

If the MA pair is too small, the variation of trends will be too frequent, and a larger pair will lead to a bigger signal delay in transactions, which means we may miss the most suitable time. Finally, I take short=5, middle $=45$, long $=90$.

In practice, I keep the parameters of KDJ unchanged, and compare the profit for 4 pairs of MA parameter. This simulation using the SSE index from 09/04/2007 to 18/05/2011. 


\begin{tabular}{|c|c|c|c|c|}
\hline MA & Pair 1 & Pair 2 & Pair 3 & Pair 4 \\
\hline Short & 3 & 5 & 10 & 15 \\
\hline Middle & 23 & 45 & 90 & 135 \\
\hline Long & 45 & 90 & 180 & 270 \\
\hline & & & & \\
\hline Net Profit & $24.36 \%$ & $66.43 \%$ & $45.85 \%$ & $-4.29 \%$ \\
\hline
\end{tabular}

\subsubsection{The KDJ Model}

After defining the trend, the KDJ will get a different threshold to transact. When we are in a bull or bear market, we can take a more radical strategy:

1) In bull market, whenever we see a death cross, just sell out your shares. If you take a wrong judgment, don't worry, the price keeps rising means there must be another golden cross, the code will purchase again.

2) In bear market, we need to know when the bear will come to an end, which time is the best time plot to buy. Therefore, first we give a threshold time to the bear market, after this time plot, we long the shares in every golden cross. You may make mistake, but the profit for one correct transaction will cover several mistakes.

3) If the market is stable, we give a threshold to the $\mathrm{D}$ line, only if the current $\mathrm{D}$ value is little enough, the golden cross is valid, and vice versa for the death cross.

The adjustable parameter for KDJ is just the number of periods to backtrack $n$, the model with a smaller $n$ will be more sensitive. I keep the other parameters and try different $\mathrm{n}$ :

\begin{tabular}{|c|c|c|c|}
\hline \multicolumn{5}{|c|}{ Restrictions } \\
\hline MA & short=5 & middle=45 & long=90 \\
\hline \multirow{3}{*}{ KDJ thresholds } & Bear market & \multicolumn{2}{|c|}{ Stable period } \\
\cline { 2 - 4 } & Period=50 & Golden & Death \\
\cline { 2 - 4 } & & D<20 & D $>80$ \\
\hline \multicolumn{5}{|c|}{ KDJ Parameter $n$} \\
\hline & $n=9 \quad n=10$ & $n=11$ \\
\hline Net Profit & $40.29 \%$ & $41.68 \%$ & $40.05 \%$ \\
\hline
\end{tabular}

Thus, I chose the $\mathrm{n}=10$.

And next step, we need to decide the value of the thresholds. I got the threshold D value from the reference, but we can make it more accurate.

\begin{tabular}{|c|c|c|c|c|c|c|}
\hline & \multicolumn{5}{|c|}{ Golen Cross } \\
\hline & & 5 & 10 & 15 & 20 & 25 \\
\hline \multirow{7}{*}{$\begin{array}{c}\text { DEATH } \\
\text { Cross }\end{array}$} & 95 & $11.64 \%$ & $10.91 \%$ & $10.91 \%$ & $10.91 \%$ & $8.64 \%$ \\
\hline & 90 & $11.64 \%$ & $10.91 \%$ & $10.91 \%$ & $10.91 \%$ & $8.64 \%$ \\
\hline & 85 & $11.64 \%$ & $10.91 \%$ & $10.91 \%$ & $10.91 \%$ & $8.06 \%$ \\
\hline & 80 & $11.64 \%$ & $10.32 \%$ & $10.32 \%$ & $10.32 \%$ & $8.06 \%$ \\
\hline & 75 & $11.64 \%$ & $10.32 \%$ & $10.32 \%$ & $10.32 \%$ & $8.06 \%$ \\
\hline & 70 & $11.05 \%$ & $10.32 \%$ & $10.32 \%$ & $10.32 \%$ & $8.06 \%$ \\
\hline & 65 & $11.05 \%$ & $10.32 \%$ & $10.32 \%$ & $10.32 \%$ & $8.06 \%$ \\
\hline
\end{tabular}


I choose two parts of stable periods, calculate the net profit rate for different parameters and take average of the two parts. Finally, I take $(5,85)$ as my thresholds.

Therefore, all the parameters have been identified, next step we will see the performance of the whole mix model.

\subsection{Simulation With the Real World Index}

I select the time period from 09/04/2007 to 29/10/2015, because it has an extreme fluctuation, and the asset graph is shown below:

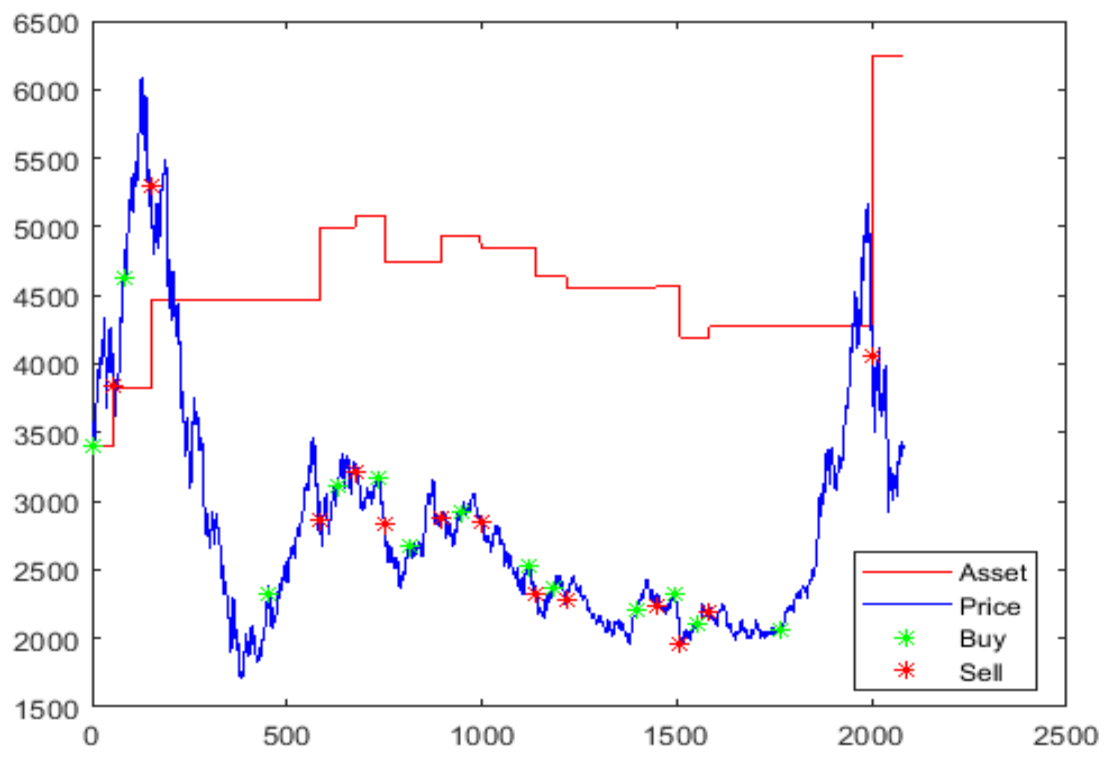

At the beginning, we are in a bull market, the code take two transactions, although all these two let us lose some profits, we still earn money at the end of this bull. Then there's a horrible long-time bear market, but the model performed extremely well: we closed out all the shares at the peak and didn't try to buy in through the whole downtrend. In the stable period we try some trades, and some can be profitable, some are losing money. And finally, there's another bull and bear, we purchase in at the bottom and escape at the peak, excellent job.

\begin{tabular}{|c|}
\hline Holding Rate \\
\hline$-0.70 \%$ \\
\hline Rate of Return \\
\hline $83.79 \%$ \\
\hline Net Return Rate \\
\hline $84.49 \%$ \\
\hline Inflation Rate \\
\hline $47.75 \%$ \\
\hline
\end{tabular}

In 8 years, the holding rate is negative, and the return rate of our model is $83.79 \%$, we win the holding rate by $84.49 \%$. Suppose the inflation rate is $5 \%$ annually, the 8 -years inflation rate is $47.75 \%$, we win the inflation by $36.04 \%$. In such a long period, I think this is successful. 


\begin{tabular}{|c|c|}
\hline Buying Time(s) & Maximum Gain \\
\hline 13 & $95.52 \%$ \\
\hline Selling Time(s) & Maximum Loss \\
\hline 13 & $-15.96 \%$ \\
\hline
\end{tabular}

Totally, we have 13 times buying-in and 13 times selling-out, 26 transactions in 8 years, I think it is acceptable. And our maximum gain in one transaction is $95.52 \%$, maximum loss is $-15.96 \%$, which is good during two horrible bear market.

\section{Conclusion}

In rapidly developing stock market, we need more accurate technical tools to help us to do transactions. In 1992, Broke, Lakonishok and LeBaron wrote Simple Technical Trading Rules and the Stochastic Properties of Stock Returns, which is very famous in technical analysis area. The tools they used are just simple VMA, FMA and TRB. If you still use VMA, FMA and TRB today, I don't think these simple tools are valid in today's stock market. Thus, the classical technical tools may not be suitable to today's market situation, we need innovation in technical analysis to handle more and more complicated situation.

Good innovation means let the indicators improve their weaknesses each other, which is my initial idea for this model. Thus, I chose KDJ for short term, which has been proved to be one of the most sensitive and valid model for short term transaction; and MA model for long term, which is the most classical model for long time trend. Combination of short and long term is just one method about complementary, I think this combination method still have a great potential.

The simulation shows the MA-KDJ model performed quite well, but there may be some deviations, because the effectiveness of the Shanghai Stock Exchange is suspicious, China stock market is not so formal to some extent. And as we all know, the technical analysis will be less effective in an information transparent market. Thus, the reliability for this model worth in-depth study.

\section{Acknowledgement}

I sincerely appreciate my supervisor Prof. Liao Lizhi, for his insightful advices and patient guiding for my dissertation. Also thanks to my senior Ren Ke although I have never met him. His dissertation under Prof. Liao in 2017 gave me the inspiration for the whole thesis.

Thanks to my teacher and friend Dr. April Luo, she gave me some useful advices for this thesis and her laughter eased my mental pressure for the tight schedule of dissertation writing.

At last, say thanks to all my classmates and friends. They accompanied me in the computer room and we worked hard for theses together. All of you, Cong Ziqiang, Fu Juzi, Lu zeqian, Huang Zihui and Huo Xiaofeng.

\section{References}

Brock, W., Lakonishok, J., \& LeBaron, B. (1992). Simple Technical Trading Rules and the Stochastic Properties of Stock Returns. Journal of Finance, 47(5), 1731-764. https://doi.org/10.1111/j.1540-6261.1992.tb04681.x

Li, Y. (2014). Statistics, Forecasting Stock Market Returns Volatility. University of Rhode Island.

Privault, N. (2014). Stochastic Finance: An Introduction with Market Examples. Chapman \& Hall/CRC Financial Mathematics Ser. https://doi.org/10.1201/b16359

Ren, K. (2017). Hong Kong Baptist University. Investment Strategy Analysis for Stocks. Undergraduate.

Schoepf, W. (2014). Business, Essays in Empirical Option, Stock, and Bond Pricing. University of Wisconsin Madison.

\section{Copyrights}

Copyright for this article is retained by the author(s), with first publication rights granted to the journal.

This is an open-access article distributed under the terms and conditions of the Creative Commons Attribution license (http://creativecommons.org/licenses/by/4.0/). 